\title{
Research article

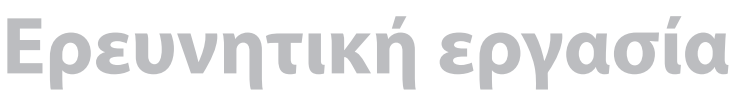

\section{The psychological impact of the COVID-19 pandemic on secondary school teachers}

\author{
P. Stachteas, ${ }^{1}$ Ch. Stachteas ${ }^{2}$ \\ ${ }^{1}$ School of Medicine, Aristotle University of Thessaloniki, Thessaloniki, \\ ${ }^{2}$ ASPETE-Department of Volos, Volos, Greece
}

Psychiatriki 2020, 31:293-301

istorically, major public health issues, such as the current COVID-19 pandemic, trigger abrupt and radical changes in daily life, thus causing severe psychological distress to the population. The ease with which the virus seems to be transmitted, combined with the exponentially rising number of new cases and the social distancing measures applied, create an atmosphere of fear and alarm. This, in turn, has a pivotal effect on the population's mental health. The aim of this study is to initially investigate the psychological effects of the new COVID-19 pandemic on secondary school teachers, who in addition to the general aggravation take on the burden of forced abstinence from their regular work duties and the simultaneous need to adapt themselves to the unprecedented process of distance learning. This is a cross-sectional study in secondary school teachers and was conducted using simple random sampling at the beginning of the pandemic in Greece. The $x^{2}$ test was used to examine associations between psychological and other variables. $34 \%$ of teachers were found to feel anxious and very anxious during the pandemic, while only $8 \%$ of teachers exhibit severe depressive emotions. It is also clear that the educators as a professional group are predominantly possessed by optimism about the outcome of the pandemic, as $71.5 \%$ was placed in the higher levels of the relevant scale. Female gender was found to have a positive correlation to feelings of fear, depression, and a negative correlation to optimism. Furthermore, a negative correlation between the teachers' high educational level and their feelings of optimism emerged from the data. This optimism may well be related with the large acceptance of the measures taken by the government to curb the expansion of the pandemic. Finally, it was found that distance teaching, which was abruptly and unpreparedly implemented by educators on account of the pandemic, was not a major concern. The findings of our study indicate a specific profile of secondary school teachers characterized by mental resilience, a quality that must be exploited and strengthened by the state with appropriate interventions in order to maximize their complex, creative work.

Key words: Pandemic, COVID-19, education, fear, depression, optimism, mental resilience. 


\section{Introduction}

The new coronavirus outbreak which originated in the city of Wuhan of the Chinese province of Hubei, quickly spread to several countries, infecting millions of people worldwide. In March 2020, the World Health Organization (WHO) declared the COVID-19 infection caused by SARS-CoV-2 a pandemic.' Such outbreaks of infectious diseases, as well as other major public health issues, frequently cause intense feelings of distress and anxiety to the general public, predominantly due to the uncertainty they bring and the sudden and radical changes in daily life they result in. ${ }^{2-6}$

The increasing number of suspected and confirmed cases, along with the constant recording of deaths caused by SARS-CoV-2 in more and more countries, Greece included, create an atmosphere of intense fear and alarm due to the very real possibility of contraction and possible manifestation of the disease.4 According to Yamazaki \& Kikkawa, ${ }^{7}$ during a pandemic the concerns can fall into three categories of danger: (a) health, (b) financial repercussions and (c) unknown. The new pandemic, therefore, apart from the danger of serious disease and possible fatality due to the COVID-19 infection, has also brought a large proportion of the global population face to face with an unprecedented, often insufferable, emotional strain, leading to panic attacks, stress disorders and feelings of depression. ${ }^{6,8,9}$

The announcement of the new coronavirus' transmissibility from human to human, the easy transmission even by asymptomatic carriers, the uncertainty over the total duration of the quarantine and the pandemic itself, the susceptibility of a wide age range and the rather frequent fatality even in patients without underlying conditions or great age, have all created feelings of fear to the majority of people who, along with their own health, also appear seriously concerned for their loved ones.10,11 According to Ahorsu et al, ${ }^{12}$ a central characteristic of pandemics of infectious diseases is the fear they can instill in large sections of the population, a fear which is capable of leading to high levels of emotional distress to healthy individuals and triggering manifestations of clinical stress disorders to the mentally vulnerable. ${ }^{9,13}$ Additionally, it has been found that the manifestation of symptoms of infection with the new coronavirus is related to increased levels of anxiety and depression, as well as decreased quality of life, all of which in turn affect health to the extent that the latter is understood as "a condition of full physical, emotional and social well-being and not simply as the absence of illness or disability". ${ }^{14}$

This situation is further complicated by the social distancing measures that are being internationally promoted, as there is a marked reduction of close communication. People are instructed to stay in their homes and limit their external activities to a minimum. Furthermore, individuals that manifest symptomatology of the disease or have a contact with an infected person, are obliged to follow the relevant isolation protocol, which renders the person more emotionally vulnerable. Indeed, it is well known that stress disorders are more likely to emerge and deteriorate in conditions of limited or no natural interpersonal contact. ${ }^{15,16}$ Misinformation, myths and conspiracy theories concerning SARS-CoV-2 that are circulated seem to have a cumulative effect on emotional distress, as they reinforce the sense of loss of control and distrust of the Authorities. ${ }^{17}$ The situation is further exacerbated by the bombardment of media reports related to the issue and the frequent emphatic references to shortage of resources, proper infrastructure and medical staff, ${ }^{18}$ contributing to the aggravation of depression. ${ }^{4,19}$

A number of international studies researching the emotional repercussions of the COVID-19 pandemic on health professionals, and vulnerable population groups in general, have been conducted..$^{5,20,21}$ However, there has not been any research on the emotional impact on students and teachers, even though similar public health crises can have various psychological effects to all the participants in the learning process, ${ }^{22}$ with feelings of fear, alarm, stress and depression being the most prominent effects. ${ }^{4,9}$

The aim of this study was a preliminary investigation of the emotional impact of the new COVID-19 pandemic on secondary education teachers who, apart from the general burden, also face the additional burden of forced absence from their teaching duties and adaptation to the new conditions of abrupt implementation of distance learning, without preparation and with limited resources. A further aim 
of this study was to outline the emotional resilience of teachers as a crucial factor of their work efficiency, as well as the effect their behaviour has on their students' emotional resilience.

\section{Material and method}

The survey was conducted on high school teachers of the municipality of Volos, who were selected via a simple random sampling process, and it consisted of an anonymous online questionnaire. Besides the 7 demographic questions (gender, age, teaching specialty, level of education, whether the individual belongs to a vulnerable group, whether a member of their family belongs to a vulnerable group, cohabitation with a minor), the questionnaire included 5 single-answer multiple choice questions: (a) Fear and stress, (b) Optimism about the outcome, (c) Depression, (d) Desire to return to work, (e) Concern over the implementation of distance learning. The questionnaire adopted the 6-point Likert scale (1: "not at all" to 6: "always") in order to avoid the concentration of selections in the middle position, which is observed when using scales with a number of redundant options. ${ }^{23}$ Content validity and face validity control and a pilot study were performed before the study leading to minor adjustments.

Since for non-large populations the size of the sample is not contingent on the size of the population, ${ }^{24-27}$ the core criterion for sample size selection was to ensure at a $5 \%$ confidence level estimation of percentages with expected accuracy of \pm 0.05 . However, because the pandemic was developing with seemingly differentiating characteristics, it was assumed that the collection of answers ought to be done under similar conditions of escalation. Consequently, the study was limited to the period from 24 to 29 of March 2020 and therefore the expected accuracy ultimately reached \pm 0.065 . For the purposes of the study teachers' specialties were grouped in two categories, "natural sciences" and "humanities".

The SPSS software was used for statistical processing and the chi-square test was performed at a significance level of $5 \%{ }^{26,28,29}$ More specifically, the existence of correlations (crosstabulation) between dependent and independent variables was checked. Demographic characteristics were defined as inde- pendent variables, and the 5 questions in the questionnaire were defined as dependent variables.

Concerning the contingency tables, it is specified that, only when in more than $20 \%$ of cells the expected frequencies are less than 5 , there is considered to be a validity problem with the chi-square test $\mathrm{t}^{28-31}$ and, as a result, the latter is not used. In cases where the chi-square test yielded a $p$ value which could not be safely used, there was a further grouping of values, taking into account the scientifically accepted thesis that their value decreases (information is lost) as the number of groups (classes) increases. ${ }^{26,32}$ Especially when there was a need to reduce the number of data classes in the six-point scale, we created a three-point scale (rather little, to some extent, rather much) by combining the successive original classes by two. As regards the educational level, the classes with values "PhD" and "Master's Degree" were combined in the class "Higher Diploma" and, similarly, the classes with values "University Degree" and "Technical School/ School of Pedagogical and Technological Education Degree" were combined in the class "Bachelor's Degree". It is worth noting that the results show only the significant correlations that emerged. ${ }^{25,33}$

\section{Results}

$63 \%$ of the participants in the study sample were women and $37 \%$ were men. $16 \%$ of teachers belonged to a vulnerable group (high-risk), 32\% lived in the same house with people belonging to a highrisk group, while $48 \%$ lived with at least one minor ( $<18$ years old). $88.5 \%$ of teachers were less than 60 years old ( $86 \%$ belong to the $40-60$ age range), and $11.5 \%$ were older than 60 years old. Regarding the teaching specialties, they were almost equally distributed, as there was only a recorded $2.7 \%$ superiority of humanities. It is worth noting that in humanities, women were four times as many as men, while in natural sciences, men were barely more than women. It is also remarkable that over one third of the teachers in the sample had a Master's Degree. Table 1 summarizes the demographic characteristics of the sample.

From the contingency tables, a correlation of stress/fear with depression $(p=0.001)$ as well as optimism ( $p=0.001)$ of teachers emerged. However, the correlation between depression and optimism was 
Table 1. Demographic characteristics of the secondary school teachers who participated in the study $(n=226$, $100 \%)$.

\begin{tabular}{|c|c|c|c|}
\hline \multicolumn{4}{|c|}{ Gender } \\
\hline \multicolumn{2}{|c|}{ Male } & \multicolumn{2}{|r|}{ Female } \\
\hline \multicolumn{2}{|c|}{$83(36.7 \%)$} & \multicolumn{2}{|r|}{$143(63.3 \%)$} \\
\hline \multicolumn{4}{|c|}{ Age } \\
\hline \multicolumn{2}{|c|}{$<60$ years old } & \multicolumn{2}{|r|}{$>60$ years old } \\
\hline \multicolumn{2}{|c|}{200 (88.5\%) } & \multicolumn{2}{|r|}{26 (11.5\%) } \\
\hline \multicolumn{4}{|c|}{ Educational level } \\
\hline PhD & Master of Science & University degree & $\begin{array}{l}\text { Technical school/School of peda- } \\
\text { gogical and technological education } \\
\text { degree }\end{array}$ \\
\hline $5(2.2 \%)$ & 75 (33.2\%) & $130(57.5 \%)$ & $16(7.1 \%)$ \\
\hline \multicolumn{4}{|c|}{ Teaching specialty } \\
\hline Natural & nd Mathematics & & Human sciences \\
\hline & $.6 \%)$ & & $116(51.4 \%)$ \\
\hline
\end{tabular}

also significant $(p=0.001)$. Nevertheless, it was found that in the contingency tables the percentage of cells with theoretical sizes of expected frequency lower than 5 is $63.9 \%$. Thus, following the performance of the Monte Carlo procedure, $p$ was found to be 0.003 , a fact which ultimately proves a correlation between depression and optimism.

Table 2 below shows the $p$ values that emerged from the chi-square test between the independent (IV) and the dependent (DV) variables. The participants' age, specialty and a family's member belonging to a vulnerable group did not seem to play a statistically significant role in the psychological burden of the participants. The male gender seems to be negatively associated with the manifestation of fear and depression and positively with the manifestation of optimistic feelings, while the educational level is negatively related to the optimism and the concern about the implementation of distance learning.

The distribution of the extent to which teachers feel fear over the spread of the SARS-CoV-2 virus is presented in table 3 . Note that $70 \%$ of teachers were included in the upper $50 \%$ of the scale. The distribution of manifestation of emotions of fear/stress in a three-point scale is demonstrated in table 4. Gender seems to affect the fear of teachers $(p=0.001)$. It is noteworthy that women express greater fear by 2.5 times more than men. Furthermore, the existence of minors in the family positively affects the stress/fear caused by the pandemic ( $p=0.04)$.

In addition, table 3 shows that feelings of optimism about the outcome of the pandemic were prevalent in our sample. The optimism expressed depends on gender $(p=0.013)$ and educational level $(p=0.025)$. The majority of teachers (60.6\%) present as moderately optimistic, with men being prevalent in the upper class by 20 percentage points over women. Regarding the educational level, more teachers of higher educational level are moderately optimistic (72.5\% over $54.1 \%$ ) while higher optimism is mostly expressed by teachers with a bachelor's degree (37.4\% over $21.3 \%$ ).

The extent to which teachers agree with the measures taken by the state in order to curb the spread of the new coronavirus is recorded in table 3 . The latter shows the overwhelming approval; in fact, the preference at a percentage higher than $50 \%$ is concentrated in the two upper classes. The particular measures at the beginning of their implementation do not appear to cause feelings of depression to teachers, since only about $8 \%$ of teachers have such feelings to a high extent.

The suspension of schools and the imposed confinement on circulation created the intense need to return to their workplace to more than half of the teachers. It is noted that, as made apparent in table 3 , 
Table 2. Correlations between demographic characteristics and psychological variables.

\begin{tabular}{lccccc}
\hline & Fear & Optimism & Depression & $\begin{array}{c}\text { Desire to return } \\
\text { to work }\end{array}$ & $\begin{array}{c}\text { Worry about } \\
\text { Distance learning }\end{array}$ \\
\hline Gender & 0.001 & 0.013 & 0.004 & 0.879 & 0.07 \\
Age & 0.782 & 0.717 & 0.954 & 0.268 & 0.436 \\
Specialty & 0.773 & 0.161 & 0.767 & 0.464 & 0.708 \\
Educational Level & 0.333 & 0.025 & 0.156 & 0.409 & 0.01 \\
Member of vulnerable group & 0.614 & 0.491 & 0.642 & 0.383 & 0.03 \\
A family's member belonging & 0.152 & 0.343 & 0.165 & 0.396 & 0.365 \\
$\quad$ to a vulnerable group & 0.04 & 0.408 & 0.948 & 0.43 & 0.241 \\
\hline
\end{tabular}

Note: $p$-values emerged from chi-square test are displayed

Table 3. Distribution of the answers ( $n, \%)$ of the 226 participants related to the psychological variables examined in a 6-point Likert scale.

\begin{tabular}{|c|c|c|c|c|c|c|}
\hline & Not at all & Rarely & A little & Sometimes & Often & Almost always \\
\hline Fear & $6(2.6 \%)$ & $16(7.1 \%)$ & 47 (20.8\%) & 79 (34.9\%) & $59(26.1 \%)$ & 19 (8.4\%) \\
\hline Optimism & $7(3.1 \%)$ & $11(4.8 \%)$ & $46(20.3 \%)$ & $91(40.3 \%)$ & $58(25.7 \%)$ & $13(5.7 \%)$ \\
\hline $\begin{array}{l}\text { Degree of acceptance } \\
\text { of restrictive measures }\end{array}$ & $0(0 \%)$ & $2(0.9 \%)$ & $20(8.8 \%)$ & $68(30.1 \%)$ & $108(47.8 \%)$ & $28(12.4 \%)$ \\
\hline Depression & 61 (27\%) & $65(28.8 \%)$ & 43 (19\%) & $38(16.8 \%)$ & $16(7.1 \%)$ & $3(1.3 \%)$ \\
\hline Desire to return to work & $8(3.5 \%)$ & $15(6.6 \%)$ & $15(6.6 \%)$ & $52(23 \%)$ & 77 (34.1\%) & $59(26.1 \%)$ \\
\hline $\begin{array}{l}\text { Worry about distance } \\
\text { learning }\end{array}$ & $41(18.1 \%)$ & $46(20.4 \%)$ & 47 (20.8\%) & $41(18.1 \%)$ & $41(18.1 \%)$ & $10(4.4 \%)$ \\
\hline
\end{tabular}

only $10 \%$ of teachers feel almost no such need. As regards the teachers' concern over the implementation (abrupt and unprepared) of distance learning - with the exception of a handful of teachers (4.4\%) expressing a very high degree of concern - the rest are approximately equally distributed $(\approx 19 \%)$ in the classes ranging from "not at all" to "very much".

Table 3 also shows the distribution of teachers according to degree of concern caused by their abrupt involvement in distance learning which, as per the Ministry's instructions, is dictated by the pandemic and the need to maintain the students' contact with the educational process. It is noted that $38 \%$ of teachers exhibit a rather normal degree of concern (low level) and roughly the same percentage records mid-level concern. The educational level seems to affect the emergence of concern over the implementation of distance learning on the part of teachers $(p=0.01)$.
Table 4 indicates that depression was correlated with gender $(p=0.004)$, with men prevailing in the lower class (69.9\% over $47.5 \%)$ and women prevailing in the other two higher classes. (54.5\% over $30.1 \%)$. Teachers with a higher level of education prevail by 20 percentage points in the class of low-level concern, whereas in the next two classes they are 10 percentage points down. Additionally, there is a significant correlation $(p=0.03)$ between worrying over the implementation of distance learning and the chance of the teacher belonging to a vulnerable group. Teachers belonging to vulnerable groups generally exhibit a higher level of concern.

\section{Discussion-Conclusions}

During the early stages of the pandemic, very little was known about the characteristics of the virus, the ways of transmission, proper prevention techniques, 
Table 4. Distribution of the answers (\%) of the participants $(n=226)$ in a 3-point Likert scale - Correlations with the gender.

\begin{tabular}{|c|c|c|c|}
\hline \multicolumn{4}{|c|}{ Fear } \\
\hline & Men & Women & $p=0.001$ \\
\hline Rather little & $12 \%$ & $8.4 \%$ & \\
\hline To some extent & $74.7 \%$ & $44.8 \%$ & \\
\hline Rather much & $13.3 \%$ & $46.8 \%$ & \\
\hline \multicolumn{4}{|c|}{ Optimism } \\
\hline & Men & Women & $p=0.013$ \\
\hline Rather little & $6 \%$ & $9.1 \%$ & \\
\hline To some extent & $50.6 \%$ & $66.4 \%$ & \\
\hline Rather much & $43.4 \%$ & $24.5 \%$ & \\
\hline \multicolumn{4}{|c|}{ Depression } \\
\hline & Men & Women & $p=0.004$ \\
\hline Rather little & $69.9 \%$ & $47.5 \%$ & \\
\hline To some extent & $22.9 \%$ & $43.4 \%$ & \\
\hline
\end{tabular}

population immunity levels, treatment and recovery, resulting in rising levels of uncertainty and fear among citizens. This was confirmed by this study, since $34 \%$ of teachers were found to experience a high and a very high degree of fear during the pandemic. In a recent research conducted in China, there were increased levels of emotional discomfort and anxiety during the COVID-19 pandemic, with 30\% reporting a great amount of these emotions and $75 \%$ experiencing fear of the possibility that the SARS-CoV-2 virus might infect their loved ones. ${ }^{6}$ The aforementioned findings are consistent with the ones of our study, which indicate that the existence of an underage child in the family has an effect on the experience of fear over the development of the pandemic.

However, our research has also shown a co-dependence between fear and depression, fear and optimism, as well as between depression and optimism. In order to define the intensity and the nature of these dependencies specialized research is required, which is beyond the scope of this study. It is worth mentioning that in Italy, two female nurses committed suicide a few days after the outbreak of the virus and it is speculated that fear of spreading the virus to patients may have played a decisive role in this outcome. ${ }^{19}$ A relevant opinion, which maintains that increasing levels of fear and concern may reduce optimism and intensify depressive feel- ings, is expressed by Montemurro ${ }^{34}$ who supports that the latter may lead to a rise in suicides in 2020. Nevertheless, it should be noted that the measures taken in Greece with the aim of limiting the spread of the new coronavirus do not initially seem to have cause depression to teachers, since only about $8 \%$ of them were experiencing high levels of such feelings.

It is also possible that fear and concern during a pandemic may play a beneficial role, as a recent study concluded that they are associated with a higher compliance with preventative measures against the spread of the new coronavirus. ${ }^{35}$ The latter is of special value for teachers, since they practice their profession in circumstances of constant interaction with large numbers of people, handling young individuals; therefore, they are at once a role model for their students and a considerable contribution to defending public health.

The findings of our study indicate a correlation between gender and the emergence of feelings of fear, depression and optimism. More specifically, a greater number of female than male teachers exhibit high levels of fear and depression, while the situation is reversed when it comes to optimism. Our findings are consistent with those of relevant studies which proved that women are more prone to exhibiting stress disorders ${ }^{36}$ and depression ${ }^{6}$ and they are more likely to show symptoms of anxiety and intense emo- 
tional discomfort than men. ${ }^{37-39}$ However, a recent study by Huang \& Zhao ${ }^{4}$ found that feelings of fear and stress, though common during the COVID-19 pandemic, are not affected by gender.

The educational level of teachers had significant impact on experiencing feelings of optimism and concern over the implementation of distance learning. Teachers with a higher level of education appear less optimistic about the outcome of the pandemic, but they are also less concerned over implementing distance learning due to the temporary suspension of schools. Both of the above could in fact be interpreted on the basis of their advanced studies, which may have given them a greater facility with the combined use of analytic-synthetic and rational thought and the exploitation of digital technology. The educational level did not seem to be related to the emergence of symptoms of depression, as indicated by other studies, ${ }^{40}$ nor to the extent of manifestation of fear over the development of the COVID-19 pandemic, ${ }^{39}$ possibly due to the fact that teachers constitute a uniform group of workers, all holding a university degree.

Several studies in the field have highlighted the relationship between age and emotional distress during the pandemic. ${ }^{39,41}$ It is supported that older age groups exhibit an increased rate of various cardiovas- cular, auto-immune and mental disorders, with social distancing and isolation leading to a greater danger due to the likelihood of stress and depression., ${ }^{7,41,42}$ This can partly be justified by the higher morbidity and mortality rates of the new coronavirus among the elderly. It is not surprising, thus, that older people in endemic areas seemed to experience a lower health-related quality of life than younger individuals. ${ }^{40}$ Even though age was expected to affect the emotional distress of teachers, our findings did not confirm this assumption. Further research is needed about physical and mental health of teachers which significantly affects their work.

The findings of this research seem to sketch a teacher profile according to which teachers are not overly afraid of the outbreak of the new coronavirus, they are not overwhelmed by pandemic-related depression, their optimism about the outcome of the crisis is prevalent and the unprecedented emergency implementation of distance learning does not cause them particular concern. Consequently, we can assume that teachers are characterized by mental resilience, a fact which is expected to positively contribute to the effectiveness of their complex work, which, as this study has made evident, they strongly hope to resume in the place and way they know best.

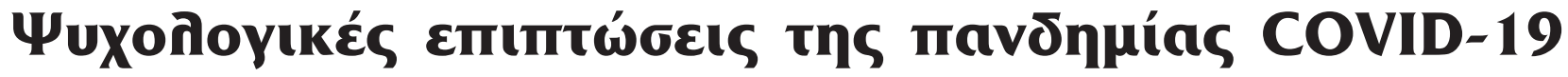

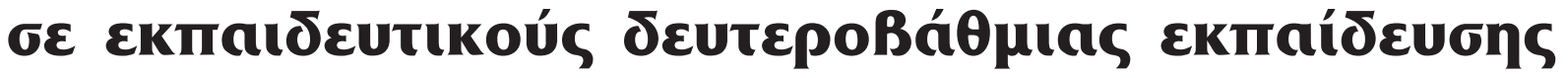

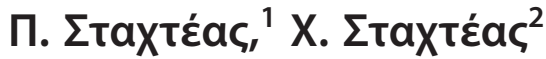

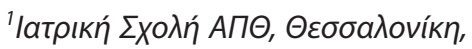

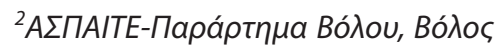

Uuxıатрıкń 2020, 31:293-301

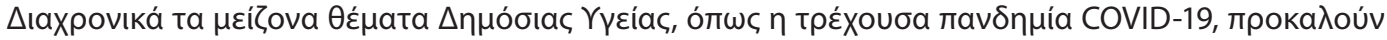

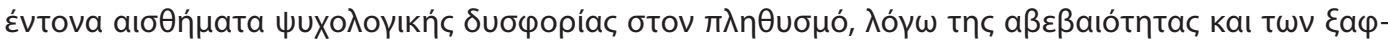

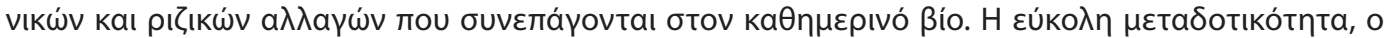

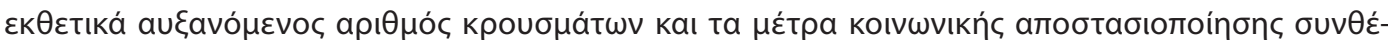

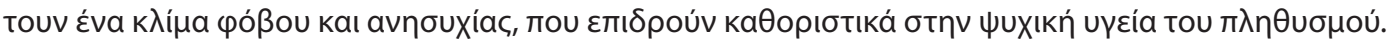

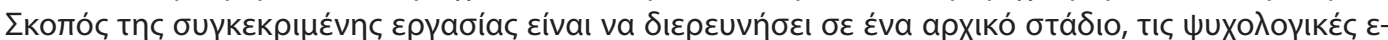

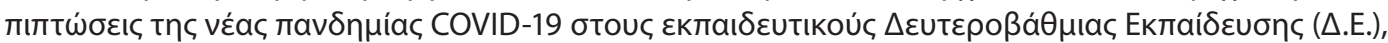

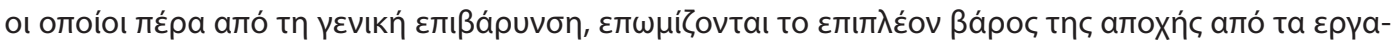




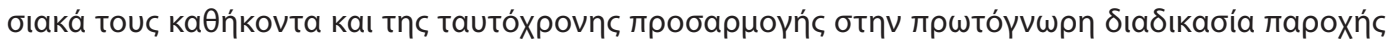

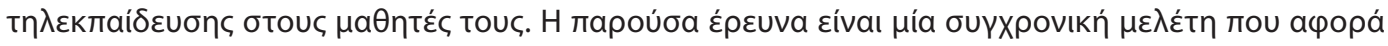

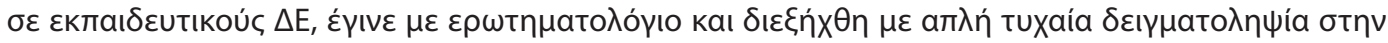

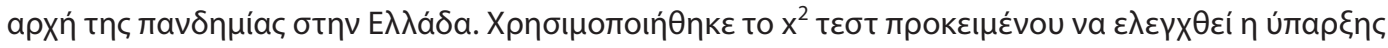

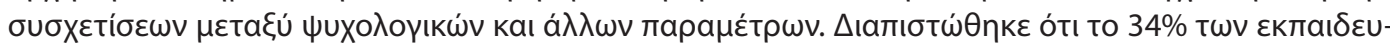

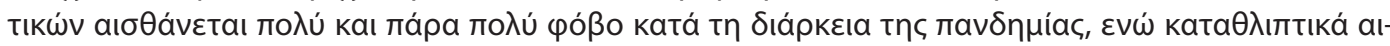

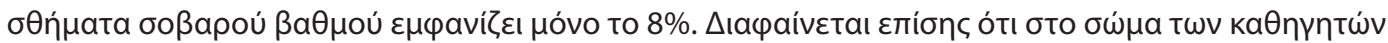

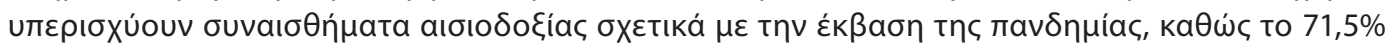

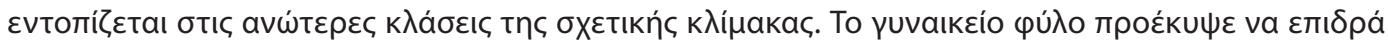

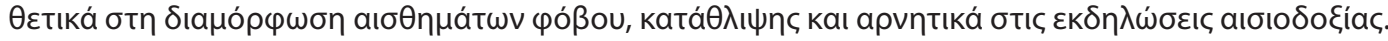

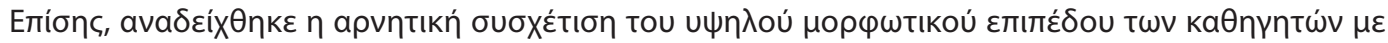

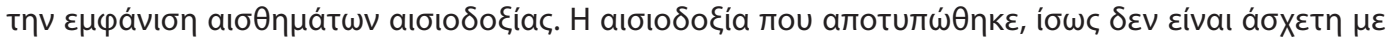

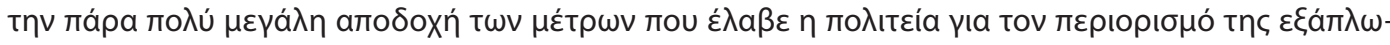

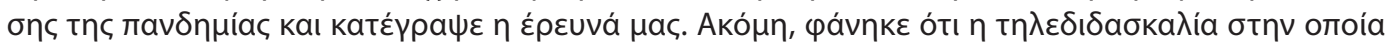

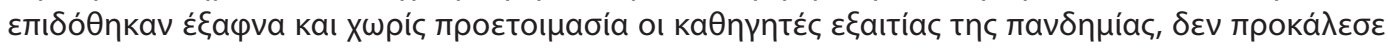

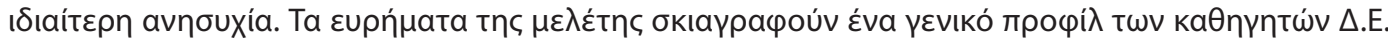

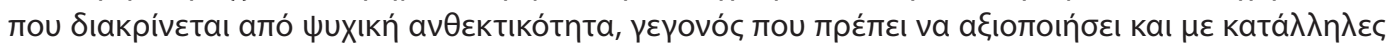

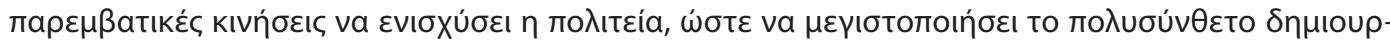
үiкó épyo touc.

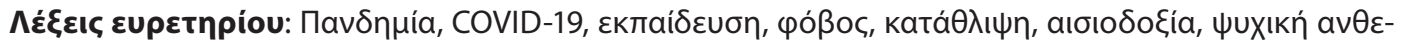
ктוкótпта.

\section{References}

1. World Health Organisation. Director-General's opening remarks at the media briefing on COVID19. March 2020

2. Taha S, Matheson K, Cronin T, Anisman H. Intolerance of uncertainty, appraisals, coping, and anxiety: The case of the 2009 H1N1 pandemic. Br J Health Psychol 2013, 19:592-605, doi:10.1111/bjhp.12058

3. Bao Y, Sun Y, Meng S, Shi J, Lu L. 2019-nCoV epidemic: address mental health care to empower society. Lancet 2020 , 395:e37-e38

4. Huang Y, Zhao N. Generalized anxiety disorder, depressive symptoms and sleep quality during COVID-19 outbreak in China: a web-based cross-sectional survey. Psychiatry Res 2020, doi:10.1016/j.psychres.2020.112954

5. Rajkumar RP. COVID-19 and mental health: A review of the existing literature. Asian J Psychiatr 2020, 52: 102066, doi:10.1016/j. ajp.2020.102066

6. Wang C, Pan R, Wan X, Tan Y, Xu L, Ho CS et al. Immediate Psychological Responses and Associated Factors during the Initial Stage of the 2019 Coronavirus Disease (COVID-19) Epidemic among the General Population in China. Int J Environ Res Public Health 2020, 17:1729, doi:10.3390/ijerph17051729

7. Yamazaki M, Kikkawa T. The structure of anxiety associated with avian influenza and pandemic influenza. Shinrigaku Kenkyu 2010, 80:476-484, doi:10.4992/j.jpsy.80.476

8. Dar KA, Iqbal N, Mushtaq A. Intolerance of uncertainty, depression, and anxiety: examining the indirect and moderating effects of worry. Asian J Psychiatr 2017, 29:129-133, doi:10.1016/j. ajp.2017.04.017
9. Kelvin DJ, Rubino S. Fear of the novel coronavirus. J Infect Dev Ctries 2020, 14:1-2, doi:10.3855/jidc. 12496

10. World Health Organization. Emergencies: Novel coronavirus. 2019, WHO, Geneva, 2020

11. Song Z, Xu Y, Bao L, Zhang L, Yu P, Qu Y et al. From SARS to MERS, Thrusting Coronaviruses into the Spotlight. Viruses 2019, 11:59, doi: 10.3390/v11010059

12. Ahorsu DK, Lin CY, Imani V, Saffari M, Griffiths MD, Pakpour AH. Fear of COVID-19 scale: Development and initial validation. Int J Ment Health Ad 2020, 1-9, doi: 10.1007/s11469-020-00270-8

13. Krueger RF, Kotov R, Watson D, Forbes MK, Eaton NR, Ruggero $\mathrm{CJ}$ et al. Progress in achieving quantitative classification of psychopathology. World Psychiatry 2018, 17:282-293, doi: 10.1002/ wps.20566

14. Constitution of the World Health Organization. In: 45th (ed) World Health Organization: Basic documents. WHO, Geneva, 2005

15. Kmietowicz Z. Rules on isolation rooms for suspected covid-19 cases in GP surgeries to be relaxed. BMJ (Clinical research ed) 2020, 368:m707, doi: 10.1136/bmj.m707

16. Xiao C. A Novel Approach of Consultation on 2019 Novel Coronavirus (COVID-19)-Related Psychological and Mental Problems: Structured Letter Therapy. Psychiatry Investig 2020, 17:175-176, doi:10.30773/pi.2020.0047

17. Xrol J, Mikuxkova EB, Cavojova V. When we are worried, what are we thinking? Anxiety, lack of control, and conspiracy beliefs amidst the COVID-19 pandemic. PsyArXiv 2020, doi:10.31234/ osf.io/f9e6p 
18. Ayittey FK, Ayittey MK, Chiwero NB, Kamasah JS, Dzuvor C. Economic Impacts of Wuhan 2019-nCoV on China and the World. J Med Virol 2020, 92:473-475, doi: 10.1002/jmv.25706

19. Goyal K, Chauhan P, Chhikara K, Gupta P, Singh MP. Fear of COVID 2019: First suicidal case in India! Asian J Psychiatr 2020, 49:101989, doi: 10.1016/j.ajp.2020.101989

20. Maunder R, Hunter J, Vicent L, Bennett J, Peladeau N, Leszcz $\mathrm{M}$ et al. The immediate psychological and occupational impact of 2003 SARS outbreak in a teaching hospital. CMAJ 2003, 168:1245-1251, PMID: 12743065

21. Xiang YT, Yang Y, Li W, Zhang L, Zhang Q, Cheung T et al. Timely mental health care for the 2019 novel coronavirus outbreak is urgently needed. Lancet Psychiatry 2020, 7:228-229, doi:10.1016/s2215-0366(20)30046-8

22. Mei SL, Yu JX, He BW, Li JY. Psychological investigation of university students in a university in Jilin Province. $J$ Med Soc 2011, 24:84-86, doi: 10.1016/j.psychres.2020.112934

23. Vamvoukas M. Introduction to Psychopedagogical Research and Methodology. Grigoris, Athens, 2007 (in Greek)

24. Benos B. Methodology for utilizing the results of Sampling. Stamoulis, Piraeus, 1985 (in Greek)

25. Psoinos D. Applied statistics. Ziti, Thessaloniki, 1989 (in Greek)

26. Chalkos G. Theory, Applications and use of statistical programs on PC. Typothito, Athens, 2007 (in Greek)

27. Zacharopoulou C. Statistics - Methods and Applications. Sofia, Thessaloniki, 2015 (in Greek)

28. Tsantas N, Moisiadis C, Bagiatis D, Chatzipantelis T. Data analysis with the help of statistical packages. Ziti, Thessaloniki, 1999 (in Greek)

29. Makrakis V. Data analysis in scientific research using SPSS. Gutenberg, Athens, 2001 (in Greek)

30. Everitt J. Analysis of Contingency Tables. Chapman \& Hall, New York, 1989

31. Symeonaki M. Statistics for everyone with SPSS. Sofia, Thessaloniki, 2015 (in Greek)

32. Katsillis I. Descriptive Statistics applied to the social sciences and education. Gutenberg, Athens, 2000 (in Greek)

33. Apostolakis I, Kastania A. Decision Making with SPSS. Stamoulis, Piraeus, 1994 (in Greek)

34. Montemurro N. The emotional impact of COVID-19: from medical staff to common people. Brain Behav Immun 2020, 1591:1-2, doi:10.1016/j.bbi.2020.03.032

35. Harper CA, Satchell L, Fido D, Latzman R. Functional fear predicts public health compliance in the COVID-19 pandemic PsyArXiv 2020, doi:10.31234/osf.io/jkfu3
36. Sareen J, Erickson J, Medved MI, Asmundson GJG, Enns MW, Stein $M$ et al. Risk factors for post-injury mental health problems. Depress Anxiety 2013, 30:321-327, doi:10.1002/da.22077

37. Guo X, Meng Z, Huang G, Fan J, Zhou W, Ling W et al. Meta analysis of the prevalence of anxiety disorders in mainland China from 2000 to 2015. Sci Rep 2016, 6:28033, doi: 10.1038/ srep28033

38. Gao W, Ping S, Liu X. Gender differences in depression, anxiety, and stress among college students: a longitudinal study from China. J Affect Disord 2020, 263:292-300, doi: 10.1016/j. jad.2019.11.121

39. Qiu J, Shen B, Zhao M, Wang Z, Xie B, Xu Y. A nationwide survey of psychological distress among Chinese people in the COVID-19 epidemic: implications and policy recommendations. Gen Psychiatr 2020, 33:e100213, doi:10.1136/ gpsych-2020-100213

40. Nguyen HC, Nguyen MH, Do BN, Tran CQ, Nguyen TTP, Pham $\mathrm{KM}$ et al. People with Suspected COVID-19 Symptoms Were More Likely Depressed and Had Lower Health-Related Quality of Life: The Potential Benefit of Health Literacy. J Clin Med 2020, 9:965, doi:10.3390/jcm9040965

41. Santini Z, Jose P, Cornwell E, Koyanagi A, Nielsen L, Hinrichsen $C$ et al. Social disconnectedness, perceived isolation, and symptoms of depression and anxiety among older Americans (NSHAP): a longitudinal mediation analysis. Lancet Public Health 2020, 5:e62-e70, doi: 10.1016/S2468-2667(19)30230-0

42. Gerst-Emerson K, Jayawardhana J. Loneliness as a public health issue: the impact of loneliness on health care utilization among older adults. Am J Public Health 2015, 105:1013-1019, doi: 10.2105/AJPH.2014.302427

Corresponding author: P. Stachteas, School of Medicine, Aristotle University of Thessaloniki, GR-541 24 Thessaloniki, Greece, Tel: (+30) 2310-999 339

e-mail: staxteasp@gmail.com 